\title{
Mumetopia interfeles sp. nov., a new species of Anthomyzidae (Diptera) occurring en masse in an urban grassy habitat in Chile: its taxonomy, phylogeny and biology
}

\author{
Jindřich ROHÁČEK ${ }^{1, *} \&$ Andrea TÓTHOVÁ ${ }^{2}$ \\ ${ }^{1}$ Silesian Museum, Nádražní okruh 31, CZ-746 01 Opava, Czech Republic. \\ ${ }^{2}$ Department of Botany and Zoology, Faculty of Science, Masaryk University, \\ Kotlářská 2, CZ-611 37 Brno, Czech Republic. \\ *Corresponding author: rohacek@szm.cz \\ 2Email: tothova@sci.muni.cz \\ ${ }^{1}$ urn:1sid:zoobank.org:author:8B3BA39C-3921-4D32-9006-B173542C2A1D \\ ${ }^{2}$ urn:1sid:zoobank.org:author:F748FF06-A0E7-422A-A775-D2494A3A9F60
}

\begin{abstract}
A new species of Anthomyzidae (Diptera), viz., Mumetopia interfeles Roháček sp. nov. (both sexes), is described from Chile, based on a large series collected from a small grassy area (consisting of a non-native species, Hordeum murinum L.) among houses in the city of Valparaíso. Its systematic affiliation, phylogenetic relationships, and biology are discussed. Cases of mass occurrence of adult Anthomyzidae, particularly those in anthropogenic habitats, are reviewed and general features of them discussed. A phylogenetic hypothesis is proposed for the relationships of the new species and the Chamaebosca group of genera within Anthomyzidae (64 species in dataset), based on Bayesian inference and maximum likelihood analyses of seven DNA markers (12S, 16S, 28S, COI, COII, CytB, ITS2). Taxonomic limits of the genus Mumetopia Melander, 1913 are discussed. Based on a new molecular hypothesis and a previous cladistic analysis of morphological data (Roháček \& Barber 2009), a broadened, better-supported concept of Mumetopia (s. str.) is proposed to include $M$. interfeles sp. nov. (and its unnamed relatives) and externally aberrant, undescribed species endemic to the Juan Fernández Islands. Apart from Anthomyzidae (M. interfeles sp. nov. only), the community of Diptera associated with $H$. murinum was dominated by phytophagous Chloropidae: Ceratobarys sacculicornis (Enderlein, 1911) occurred in extremely high numbers similar to those of $M$. interfeles sp. nov., while the less abundant Opetiophora sp. represents the first record of the genus from South America.
\end{abstract}

Keywords. Acalyptratae, anthomyzid flies, taxonomy, DNA sequences, relationships, habitat and hostplant affinity, Chloropidae, Hordeum murinum.

Roháček J. \& Tóthová A. 2021. Mumetopia interfeles sp. nov., a new species of Anthomyzidae (Diptera) occurring en masse in an urban grassy habitat in Chile: its taxonomy, phylogeny and biology. European Journal of Taxonomy 731: 135-158. https://doi.org/10.5852/ejt.2021.731.1211 


\section{Introduction}

During a visit to Valparaíso city (Chile) in February 2018, Dr Michael von Tschirnhaus recorded anthomyzid flies occurring in huge numbers in a small grassy spot in the shared backyard of the house of his son Jakob von Tschirnhaus. As an experienced dipterist, who has collected flies in various habitats all over the world, he recognized that a mass occurrence of Anthomyzidae, moreover in a built-up city area, is a very unusual phenomenon and, therefore, collected a series of several hundred specimens for subsequent research.

Indeed, extremely high numbers of a species of Anthomyzidae are rarely encountered and collected. In the Oriental tropics (Indonesia: Flores Island), M. von Tschirnhaus collected more than 500 specimens of Amygdalops cuspidatus Roháček, 2008 in herbaceous vegetation grazed by buffaloes in a cultivated landscape (Roháček 2008: 349). There are several examples of relatively high densities of Anthomyzidae recorded in North America (Canada) (K.N. Barber, pers. com. 2020), with fewer than 300 specimens found in small sites, e.g., Quametopia terminalis (Loew, 1863) with 196 specimens swept from a small growth $\left(20 \mathrm{~m}^{2}\right)$ of Impatiens capensis Meerb. under Betula/Populus in an urban park (cf. Roháček \& Barber 2011), Anthomyza gilviventris Roháček \& Barber, 2016 with 218 specimens swept from about $30 \mathrm{~m}^{2}$ of Scirpus microcarpus J.Presl \& C.Presl on a residual sedge meadow (an undeveloped urban site), A. vockerothi Roháček \& Barber, 2016 with 253 specimens swept from about $100 \mathrm{~m}^{2}$ of emergent Equisetum fluviatile L. with Carex on a marshy outflow, A. equiseti Roháček \& Barber, 2016 with 220 specimens reared from dry stalks of Equisetum fluviatile taken from about $30 \mathrm{~m}^{2}$ of a floodplain of a marshy area (see also Roháček \& Barber 2016), and Carexomyza marshalli Barber \& Roháček, 2020 with 185 specimens swept from $60-70 \mathrm{~m}^{2}$ of Carex utriculata Boott with cf. Poa pratensis L. on a natural sedge meadow (Barber \& Roháček 2020). In Europe, only some species of Stiphrosoma Czerny, 1928 can sometimes occur in large numbers (Roháček 2009: 117), particularly S. laetum (Meigen, 1830) of which hundreds of specimens were reared from a few tufts of various graminoids in N Germany (Roháček 2006: 298, summary data only). For example, a total of 434 specimens was obtained by H. Meyer from 6 samples of a mixture of mostly Agrostis stolonifera L., Glyceria maxima (Hartm.) Holmb. and Deschampsia caespitosa (L.) P.Beauv., with a few other species of grasses, taken from a total area of $1.7 \mathrm{~m}^{2}$ in natural rivershore habitat in Schleswig-Holstein (detailed unpublished data obtained from H. Meyer by M. von Tschirnhaus, pers. com. 2020).

Interestingly, the anthomyzid fly occurring so abundantly in a residential area of Valparaíso proved to be an unnamed species of the Chamaebosca group of genera (sensu Roháček \& Barber 2009); following results from examination of the male and female terminalia, it has been affiliated with the genus Mumetopia Melander, 1913. Thanks to a large and well-preserved series of specimens (partly in pure ethanol), we were not only able to describe this new species (see below) but also to resolve its relationships by means of molecular data analyses.

The systematic limits of the genus Mumetopia remain unresolved up to the present date. Melander's (1913) original concept of the genus covering three species, viz., M. occipitalis Melander, 1913 (type species), M. nigrimana (Coquillett, 1900) and M. terminalis (Loew, 1863), proved to be untenable because of excessive heterogeneity. Roháček \& Barber (2009) first recognized that these species are not closely related, and found that only the first two belong to the Chamaebosca group of genera (a clade comprising the genera Chamaebosca Speiser, 1903, Mumetopia and Stiphrosoma), while M. terminalis was found to be unrelated to any of them and was later designated by Roháček \& Barber (2011) as the type species of a new genus, Quametopia Roháček \& Barber, 2011. Furthermore, based on analysis of morphological data, they recognized M. nigrimana (and its numerous undescribed Neotropical relatives) to be most closely related to species of Stiphrosoma, not to M. occipitalis. Subsequent phylogenetic hypotheses based on analyses of molecular data (Roháček \& Tóthová 2014; Roháček et al. 2019) have confirmed the above relationships. Currently, there are four named species affiliated with the genus 
Mumetopia, but only three of them belong, in fact, to the genus (in the restricted concept, see Roháček \& Barber 2009), viz., M. occipitalis (widespread in North America), M. messor Roháček \& Barber, 2009 (Ecuador) and M. taeniata Roháček \& Barber, 2009 (Colombia). The new species from Chile also seems to belong to this alliance. The remaining species, M. nigrimana, is derived from a different lineage, tentatively termed the M. nigrimana group, that is allied to Stiphrosoma. It is to be stressed that both Mumetopia (s. str.) and, particularly, the M. nigrimana group comprise a number of undescribed species (cf. Roháček \& Barber 2009; Barber \& Roháček 2010) in the Neotropical Region.

\section{Material and methods}

\section{Material}

The material examined is deposited in the following institutional collections:

$\mathrm{CNCI}=$ Canadian National Collection of Insects, Arachnids \& Nematodes, Ottawa, ON, Canada

SDEI = Senckenberg Deutsches Entomologisches Institut (Senckenberg German Entomological Institute), Müncheberg, Germany

SMOC $=$ Slezské zemské muzeum, Opava, Czech Republic

ZSMC = Zoologische Staatssammlung München, München, Germany

The material was originally preserved in ethanol ( $70 \%$ and $96 \%)$, but the majority of the specimens were dried using equal volumes of ethyl acetate and $96 \%$ ethanol and subsequently pure ethyl acetate (each for a few hours), and mounted on triangular pinned paper points during the course of this work. Abdomens of a number of specimens were detached, cleared by boiling for several minutes in a $10 \%$ solution of potassium hydroxide $(\mathrm{KOH})$ in water, then neutralized in a $10 \%$ solution of acetic acid $\left(\mathrm{CH}_{3} \mathrm{COOH}\right)$ in water, washed in water and subsequently transferred to glycerine. Postabdominal structures were dissected and examined in a drop of glycerine under binocular microscopes (Reichert, Olympus SZX10). Detailed examinations of genital structures were performed with a compound microscope (JENAVAL). After examination, all dissected parts were put into small plastic tubes containing glycerine, sealed with hot forceps and pinned below the respective specimens.

\section{Drawing techniques and photography}

Legs were drawn on squared paper using a Reichert binocular microscope with an ocular screen. Details of the male and female genitalia and all preimaginal stages were drawn by means of an Abbe's drawing apparatus on a compound microscope (JENAVAL) at larger magnification $(130-500 \times)$. Wings were photographed using an Olympus BX51 compound microscope with an attached digital camera (Canon EOS 1200D). Whole adult specimens and their details were photographed by P. Krásenský by means of a Canon 5D Mark II digital camera with a Nikon CFI Plan $10 \times / 0.25 \mathrm{NA} 10.5 \mathrm{~mm}$ WD objective attached on a Canon EF 70-200 mm f/4L USM lens. The specimens were moved upwards between each exposure using a WeMacro Rail (http://www.wemacro.com/, each step was $0.01 \mathrm{~mm}$ ) and the final photographs were stacked from multiple layers using Zerene Stacker. The final images were edited in Adobe Photoshop CS6.

\section{Measurements}

Five main characteristics of adults (dry mounted) were measured: body length (measured from anterior margin of head to end of cercus, thus excluding the antenna), wing length (from wing base to wing tip), wing width (maximum width), C-index $\left(\mathrm{Cs}_{3}: \mathrm{Cs}_{4}\right)$ (= ratio of length of $3^{\text {rd }}$ costal sector: length of $4^{\text {th }}$ costal sector) and index $\mathrm{r}-\mathrm{m} \backslash \mathrm{dm}-\mathrm{cu}: \mathrm{dm}-\mathrm{cu}$ (= ratio of length of section between $\mathrm{r}-\mathrm{m}$ and $\mathrm{dm}$-cu on discal cell: length of dm-cu). The holotype and 20 paratypes ( 3 large, 4 medium, 3 small specimens of each sex) were measured. 


\section{Molecular analyses}

\section{Taxon sampling}

The analysed dataset contains 67 species (64 Anthomyzidae +3 outgroup taxa). All taxa for which specimens were available for DNA extraction were included in the molecular analysis. Except for two additions (M. interfeles sp. nov. and Stiphrosoma stylatum Roháček \& Barber, 2005), they are listed in full (with names, authors and source localities of analysed specimens) in Roháček et al. (2019: table 1, most species) and Barber \& Roháček (2020: table 1, species of Carexomyza Roháček, 2009 only). We used one specimen per species except for an unnamed species of the M. nigrimana group, of which we processed two specimens. The outgroup included Geomyza tripunctata Fallén, 1823 and Opomyza florum (Fabricius, 1794) (Opomyzidae, the sister family of the Anthomyzidae, cf. Roháček 1998, 2006), and Clusia flava (Meigen, 1830) (Clusiidae, considered to be the most generalized family of the Opomyzoidea, cf. McAlpine 1989) which was used to root the phylogenetic trees.

\section{DNA extraction, PCR and sequencing}

The adult flies used for analysis were air-dried or ethanol-preserved. The molecular procedures and protocols are fully documented in Roháček et al. (2019). GenBank accession numbers for the sequences are listed in Roháček et al. (2019: 748-750, table 1) and Barber \& Roháček (2020: 72, table 1) so only those of M. interfeles sp. nov. and S. stylatum are listed here (Table 1).

\section{Alignment and phylogenetic analyses}

Alignment protocols are fully outlined in Roháček et al. (2019). The final dataset consisted of 68 specimens as terminal 'taxa' (67 species) and 4583 characters: $12 \mathrm{~S}-349 \mathrm{bp}, 16 \mathrm{~S}-361 \mathrm{bp}, 28 \mathrm{~S}-$ 614 bp, COI - 1248 bp, COII - 633 bp, CytB - 646 bp, ITS2 - 732 bp. Both Bayesian inference (MrBayes ver. 3.2) and maximum likelihood (RAxML ver. 8.2.12) analyses were performed (for details see Roháček et al. 2019). The node support values are given with the posterior probability (PP) above the nodes (if value $>0.5$ ) and the bootstrap value (BV) below the nodes in the resulting tree depicted in Fig. 32. For the Bayesian analysis all parameters were unlinked across partitions. The convergence of the runs was assessed by checking the potential scale reduction factor (PSRF) values of each parameter (in all cases, approaching 1000) and the standard deviation of split frequencies $(<0.01)$. The mean loglikelihood value for the best-fit BI tree was -43485.44 ; for the RAxML tree, it was -45029.093091 . The resulting phylogenetic tree (consensus tree) was visualized using Interactive Tree Of Life (iTOL; Letunic \& Bork 2019).

\section{Morphological terminology}

The terminology follows that used in monographs of Anthomyzidae by Roháček (2006) and/or Roháček \& Barber (2016) including terms of the male hypopygium and female terminalia except that "orbit" is replaced here with "orbital plate". For male genitalia terminology, the 'hinge' hypothesis of the origin of the eremoneuran hypopygium (see Zatwarnicki 1996) has been adopted. The following synonymous terms of the male genitalia emanating from other hypotheses and used in recent manuals of Diptera (Cumming \& Wood 2009, 2017) and / or the monograph of Griffiths (1972) need to be listed (terms used here first): aedeagus $=$ phallus; ejacapodeme $=$ ejaculatory apodeme; epandrium $=$ periandrium; gonostylus $=$ surstylus, telomere; medandrium $=$ bacilliform sclerite, intraepandrial or intraperiandrial sclerite; phallapodeme $=$ aedeagal apodeme; postgonite $=$ gonite, paramere. Morphological terms of the male postabdomen and genitalia are depicted in Figs 4-8, 10-11 and 13, those of the female postabdomen in Figs 17, 19-20 and 23-25. 
ROHÁČEK J. \& TÓTHOVÁ A., A mass-occurring new species of Anthomyzidae (Diptera) from Chile

Table 1. Two species added to our dataset of Anthomyzidae used for the molecular analyses, with their GenBank accession numbers.

\begin{tabular}{lcc}
\hline species & $\begin{array}{c}\text { Mumetopia interfeles } \\
\text { Roháček sp. nov. }\end{array}$ & $\begin{array}{c}\text { Stiphrosoma stylatum } \\
\text { Roháček \& Barber, 2005 }\end{array}$ \\
\hline locality & Chile & Canada (Ontario) \\
12S & MT653088 & MT653089 \\
16S & MT653086 & MT653087 \\
COIa & MT648503 & MT648509 \\
COIb & MT648502 & MT648510 \\
COII & MT755645 & MT755646 \\
CytB & MT755647 & MT755648 \\
28S & MT653090 & MT653091 \\
ITS2 & MT653083 & MT644859 \\
\hline
\end{tabular}

Abbreviations of morphological terms used in text and/or figures

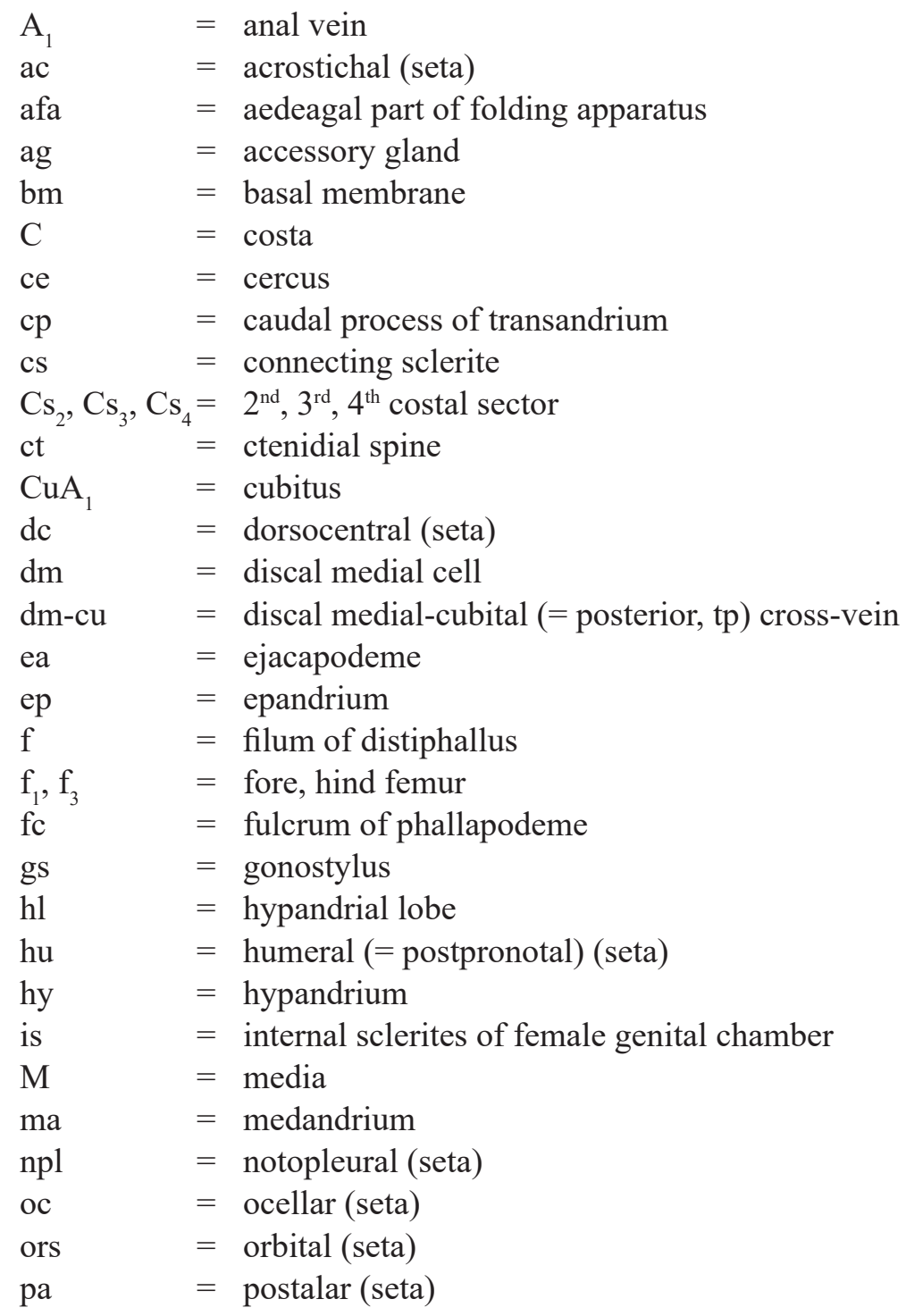




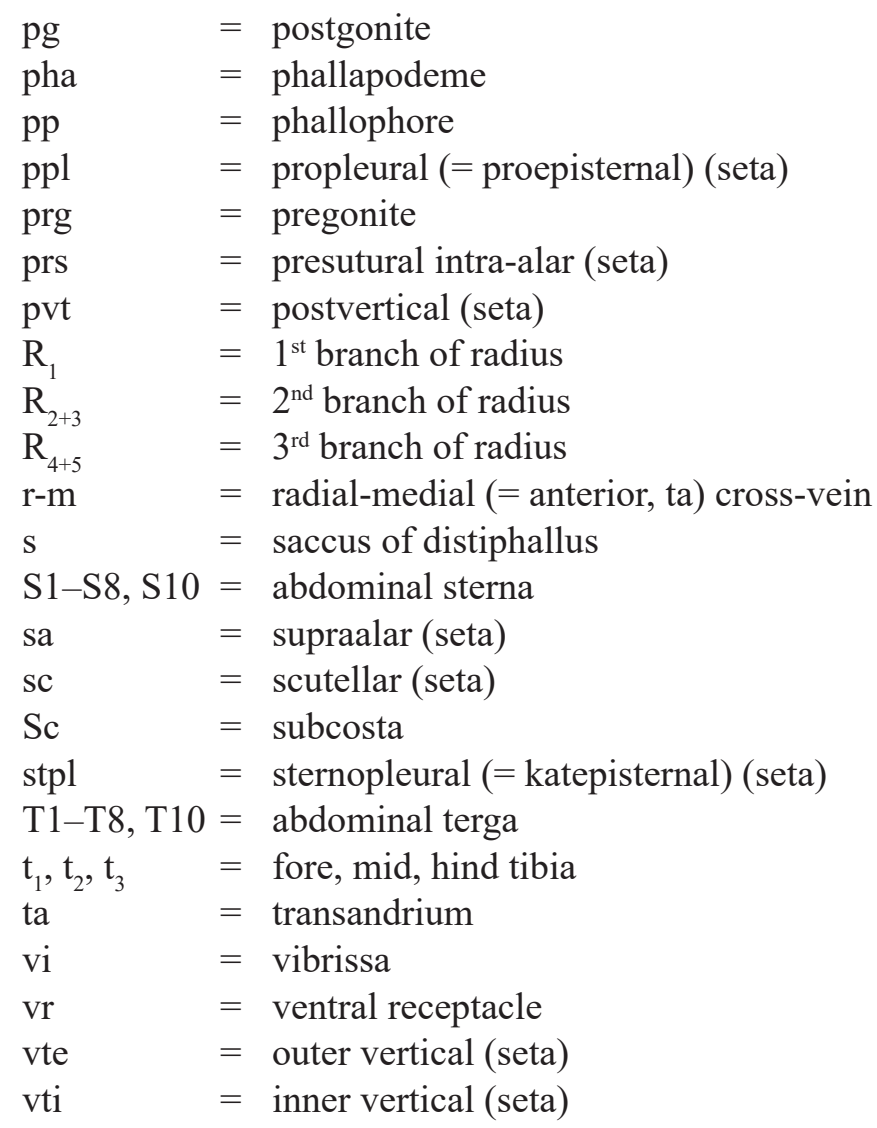

\section{Results}

Phylum Arthropoda Latreille, 1829

Class Insecta Linnaeus, 1758

Order Diptera Linnaeus, 1758

Infraorder Muscomorpha Crampton, 1944

(unranked) Eremoneura Lameere, 1906

(unranked) Cyclorrhapha Brauer, 1863

Superfamily Opomyzoidea Hendel, 1916

Family Anthomyzidae Czerny, 1903

Subfamily Anthomyzinae Czerny, 1903

Genus Mumetopia Melander, 1913

Mumetopia interfeles Roháček sp. nov. urn:1sid:zoobank.org:act:6843969E-C0DB-46A3-9503-17FA25555D55

Figs $1-28$

\section{Differential diagnosis}

Owing to its bicoloured (blackish brown and yellow) body, normal wings and a solid silvery microtomentose occipital (supracervical) patch, M. interfeles sp. nov. most closely resembles $M$. occipitalis Melander, 1913. However, it differs from the latter species by a shorter frontal triangle with strongly acuteangled anterior corner (ending at most in the anterior fourth of frons), ocellar triangle with the same sparse microtomentum as on the frontal triangle (densely grey microtomentose and contrasting with glabrous frontal triangle in M. occipitalis), strong anterior ors, very shortly ciliate (not pectinate) arista and dorsomedially broadly yellow female preadominal terga. There are also distinct dissimilarities in 
some structures of the male genitalia (gonostylus more slender; medandrium with dorsolateral corners slightly projecting; aedeagal part of folding apparatus with tuberculiform excrescences finer; filum bare and with shorter, curved and pointed projection in distal fourth) and in the female postabdomen (T7 dorsomedially widely divided; S7 pale-pigmented and elongate; posterior pair of internal sclerites in female genital chamber markedly shorter). The other two species of Mumetopia (s. str.), viz., M. messor and $M$. taeniata, are yet more different from $M$. interfeles sp. nov., not only in having strongly shortened and narrowed wings, reduced halteres and narrowed thorax (see Roháček \& Barber 2009: figs 17$18,20-21$ ) but also the head almost entirely brown, occiput with silvery patch absent and uniformly dark brown, preabdominal sterna in both male and female brown and male and female terminalia more resembling those of M. occipitalis.

\section{Etymology}

The name 'interfeles' (= 'among cats' in Latin) refers to the discovery of the new species in an urban grassy habitat much favoured by cats (see Fig. 31).

\section{Material examined}

\section{Holotype}

CHILE $\bullet 1$ ' ; labeled "CHILE: Valparaíso city: Cerro O'Higgins, Avenida George Washington 1260D, $33^{\circ} 03^{\prime} 22.7^{\prime \prime} \mathrm{S}, 71^{\circ} 35^{\prime} 45.5^{\prime \prime} \mathrm{W}$, M. von Tschirnhaus leg.", "Cl 2230, $109 \mathrm{~m}, 27 . i \mathrm{i} .2018$, swept from grass in courtyard at house of Jakob von Tschirnhaus", "Holotypus ${ }^{\Uparrow}$ Mumetopia interfeles sp. n., J. Roháček det. 2020 [red label]"; SMOC MIT001. The specimen is intact, in good condition (see Fig. 1).

\section{Paratypes}

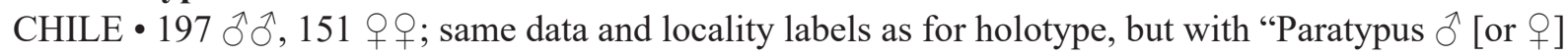

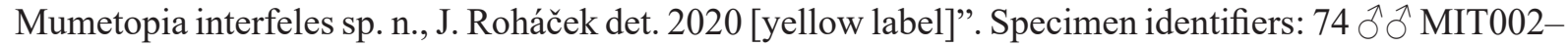
MIT075 and 75 우 MIT076-MIT150; SMOC; 10 o $^{\Uparrow}$ MIT151-MIT160 and 10 우 MIT161-MIT170;

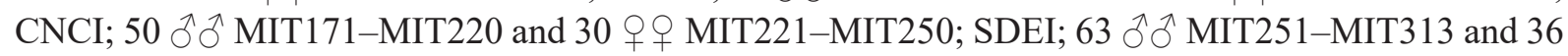
우은IT314-MIT349; ZSMC.

Other material (excluded from type series)

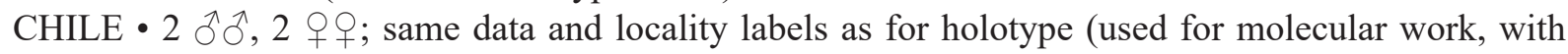
remnants preserved in ethanol or glycerine). Specimen identifiers: $2 \widehat{\partial} \widehat{\widehat{O}}$ MIX001, MIX002; 2 우 MIX003, MIX004; SMOC.

CHILE -3 q $q$; same data and locality labels as for holotype (specimens without head or abdomen). Specimen identifiers: 3 우 MIX005-MIX007; SMOC.

\section{Description}

$$
\text { Male }(n=200)
$$

TOTAL BODY LENGTH. $1.59-2.06 \mathrm{~mm}$.

Colouration. Body distinctly bicolourous (Fig. 1), ventrally yellow, dorsally largely brown to blackish brown and relatively shiny, particularly on mesonotum and sides of preabdominal terga.

HEAD (Figs 1, 3). Slightly higher than long, also bicolourous, yellow and blackish brown. Frons largely dull yellow, with only frontal triangle and posterior marginal part at occiput dark brown and shiny. Frontal triangle relatively large, well delimited (Fig. 3) and with acute anterior corner reaching to anterior fourth of frons, very sparsely greyish-brown microtomentose including ocellar triangle and hence shining; ocellar triangle very slightly elevated; ocelli rather small and oc inserted somewhat outside margin of ocellar triangle. Frontal lunule small, reduced and depressed, darker yellow than adjacent frons. 
Orbital plate relatively broad, pale yellow and well delimited due to silvery white microtomentum up to posterior ors; more posteriorly it is narrowed, gradually darkened and with microtomentum reduced, becoming brown to dark brown and somewhat shining in front of vti and vte. Occiput concave, entirely blackish brown, mostly very sparsely dark-grey microtomentose and hence shining, except for distinctive, densely silvery-white microtomentose and glittering medial patch (somewhat higher than broad) between pvt and foramen (Fig. 3). Face narrow and slightly depressed, dull yellow to ochreous yellow and on sides bordered by very fine darker ochreous stripe. Parafacialia and anterior half of gena pale yellow and silvery-white microtomentose; posterior half of gena and postgena yellow, with microtomentum reduced, particularly ventrally; gena and postgena ventrally narrowly ochreous-brown margined. Mouthparts yellow to pale ochreous, palpus pale yellow. Cephalic chaetotaxy (Figs 1, 3): all macrosetae relatively strong but pvt small and weak, strongly convergent, sometimes with apices meeting medially; vte, vti, oc and posterior ors usually subequal, long (longest of cephalic setae) and rather robust or vti slightly longer and/or posterior ors slightly shorter; oc dorsoproclinate and slightly divergent; 2 strong ors (aberrantly 3 ors on one side of frons, cf. Fig. 14) but anterior shorter than (twothirds to three-fourths length of) posterior; 1 or 2 microsetulae in front of anterior ors; usually 2 pairs of minute medial microsetulae just in front of anterior corner of frontal triangle; vi long but shorter than posterior ors and usually longer than anterior ors; subvibrissa well developed, up to two-thirds of vi length but markedly weaker; 3 or 4 short peristomal setulae; postgena with a few small dark setulae

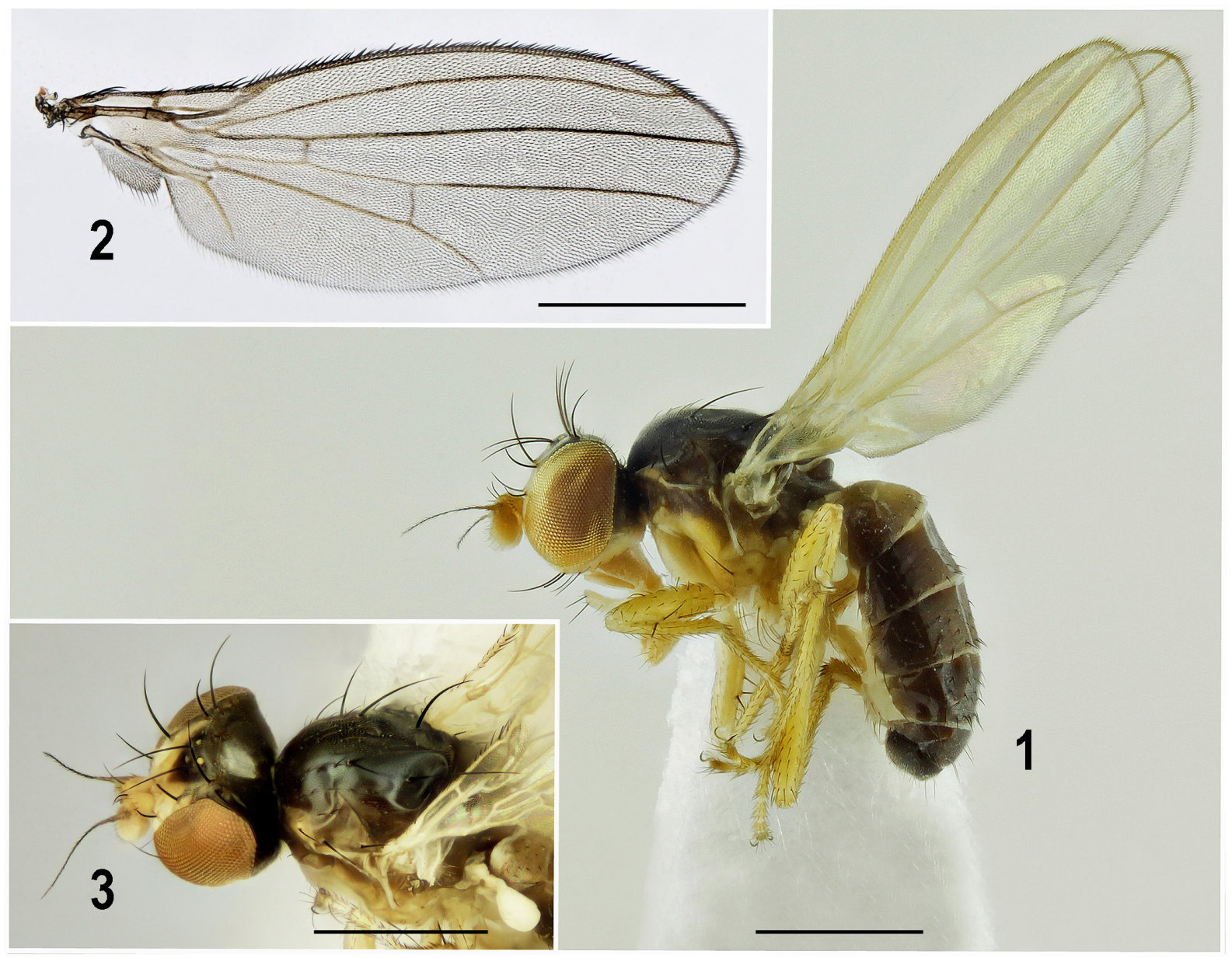

Figs 1-3. Mumetopia interfeles Roháček sp. nov., đ̂. 1. Holotype (SMOC MIT001), lateral view. 2. Right wing, paratype (SMOC MIT003). 3. Head and thorax, paratype (SMOC MIT002), laterodorsal view. Scale bars $=0.5 \mathrm{~mm}$. Photos by P. Krásenský. 
and 2 short pale setae in posteroventral corner; postocular microsetulae minute, sparse, in single row; 1 inclinate setula behind bases of vte and vti also present. Eye with very short and very sparse pilosity (visible in ventral half of eye), ellipsoid to suboval; its longest (oblique) diameter about 1.5-1.6 times as long as shortest diameter; gena short, its shortest height $0.09-0.11$ times as long as shortest eye diameter. Palpus with a few setulae in addition to dark, relatively long and anteroventrally to ventrally directed preapical seta (Fig. 1). Antenna strongly geniculate, entirely yellow (Figs 1, 3), at most $1^{\text {st }}$ flagellomere somewhat (narrowly) darkened around base of arista; $1^{\text {st }}$ flagellomere laterally compressed; its anteroventral margin with cilia (darker dorsally, pale to whitish ventrally) almost twice as long as those of arista. Arista about 2.1 times as long as antenna, dark brown with ochreous to brown basal segment, and very short dark ciliate.

THORAX. Distinctly narrower than head. Mesonotum largely blackish brown but laterally (above notopleural area and wing) brown; humeral callus (= postpronotum) yellow to ochreous (Fig. 3), rarely brownish darkened (see Fig. 1, holotype); notopleural area usually darker, ochreous to brown. Mesonotum shining but with very sparse greyish microtomentum. Pleural part of thorax largely yellow, only dorsally with brownish (often interrupted) stripe running from neck to base of abdomen (Fig. 1, cf. also Fig. 14); pleuron with microtomentum denser and hence subshiny. Thoracic chaetotaxy (Figs 1, 3): 1 short and weak hu (as long as or shorter than posterior npl) and 2 microsetae on humeral callus; $2 \mathrm{npl}$, anterior long, twice as long as posterior npl; prs small, yet shorter and weaker than hu; 1 short sa (as long as posterior $\mathrm{npl}$ ) and 1 distinctly longer pa; 2 strong and very long postsutural dc; anterior $\mathrm{dc}$ inserted just behind suture (thus very anteriorly) and only slightly shorter than posterior dc; posterior dc and apical sc longest of thoracic setae; only 2 or $3 \mathrm{dc}$ microsetae in front of anterior dc but that closest to latter often enlarged (sometimes longer than prs); ac microsetae few in number, in only 2 medial short rows, never reaching level of posterior dc; $2 \mathrm{sc}$, basal very short and weak, apical sc very long, as long as posterior dc; ppl reduced to minute (often hardly visible) microseta; 2 stpl, both relatively long although posterior longer and thicker; 1 (rarely 2) microseta in front of anterior stpl and 3-5 below them; 2 or 3 longer dark setulae also in ventral corner of sternopleuron. Scutellum medium long, rounded triangular, with distinctly convex disc; postscutellum well developed, strongly convex (Fig. 1).

LEGS. Yellow with coxae, bases of femora and knees usually paler; only terminal segment of all tarsi partly or entirely pale-brown darkened. $f_{1}$ with ctenidial spine rather variable in length (as long as to distinctly longer than maximum width of $t_{1}$ ) and inserted near (anteroventral to) longest seta of posteroventral row of setae (cf. Figs 1, 14, 22); fore basitarsus with 3 (rarely 4) longer but relatively fine setulae ventrobasally. $t_{2}$ with relatively short but distinct ventroapical seta (Fig. 26). $f_{3}$ with 5 or (less often) 6 thickened and shortened setae in distal half of posteroventral row (Fig. 28); hind basitarsus with 2 or 3 thickened ventrobasal setulae (Fig. 27).

WING (Fig. 2). Not very long compared to body length. Wing membrane pale brownish-ochreous, veins pale brown. $C$ reaching to apex of $M$, in sector $\mathrm{Cs}_{2}$ (between apices of $R_{1}$ and $R_{2+3}$ ) with sparse but distinct spinulae in addition to usual setulae. $\mathrm{R}_{1}$ robust and short, with preapical kink (fusion of Sc and $\mathrm{R}_{1}$ ) well developed. $\mathrm{R}_{2+3}$ long, proximally bent along $\mathrm{C}$, distally upcurved to it, thus somewhat sinuate. $\mathrm{R}_{4+5}$ slightly to indistinctly bent (recurved) and ending close to apex of wing. M slightly bent to straight, very slightly divergent from $\mathrm{R}_{4+5}$ and ending far from apex of wing. Cross-vein $\mathrm{r}-\mathrm{m}$ situated slightly to distinctly in front of middle of $\mathrm{dm}$ cell. Cross-vein $\mathrm{dm}$-cu much shorter than terminal part of $\mathrm{CuA}_{1}$. Basal and posterior cubital cells distinct but narrow. $\mathrm{CuA}_{1}$ almost reaching to wing margin, $\mathrm{A}_{1}$ short and ending far from it. Anal lobe and alula well developed, the latter not narrowed. Wing measurements: length 1.55-1.95 mm, maximum width $0.52-0.70 \mathrm{~mm} ; \mathrm{Cs}_{3}: \mathrm{Cs}_{4}=1.09-1.35 ; \mathrm{r}-\mathrm{m} \backslash \mathrm{dm}-\mathrm{cu}: \mathrm{dm}-\mathrm{cu}=$ 2.64-3.42. Haltere with yellow to ochreous stem and almost white knob (Fig. 3). 

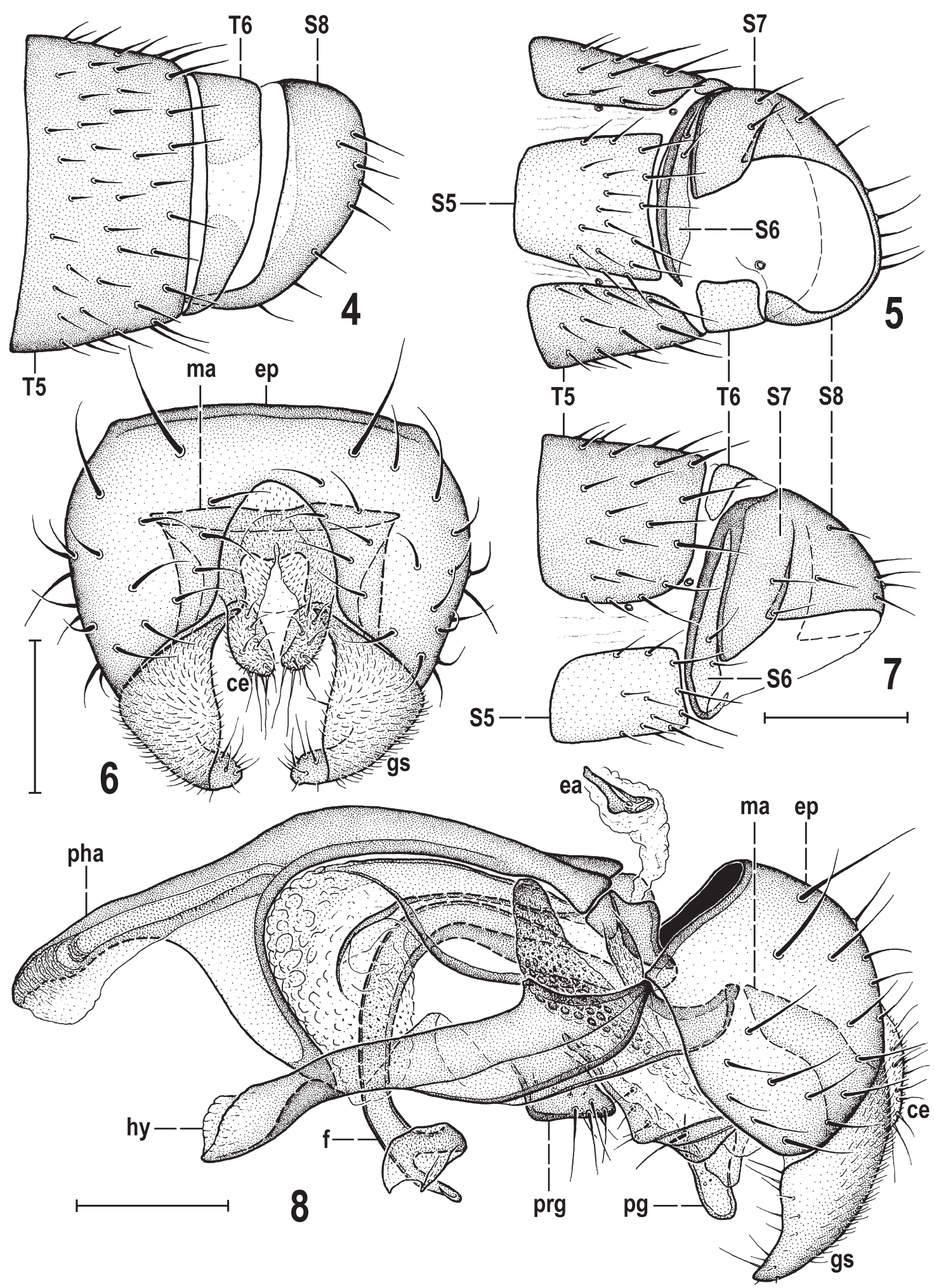

Figs 4-8. Mumetopia interfeles Roháček sp. nov., male paratypes (SMOC MIT004-MIT007). 4. Postabdomen with fifth abdominal segment, dorsal view. 5. Same, ventral view. 6. External genitalia, caudal view. 7. Postabdomen with fifth abdominal segment, lateral view. 8. Genitalia, lateral view. Scale bars: $4-5,7=0.2 \mathrm{~mm} ; 6,8=0.1 \mathrm{~mm}$. For abbreviations see Material and methods. 
ABDomen. In dorsal view about as wide as thorax. Preabdominal terga brown to blackish brown, T2-T5 relatively large and broad, bent far onto lateral sides of abdomen (Fig. 1), with short and relatively strong but sparse setae. Basal terga usually medially pale brown(T2) to ochreous (T1), also T3 and T4 somewhat lighter dorsomedially (i.e., brown) than laterally (blackish brown). Lateral parts of T2-T5 sparsely microtomentose and more shining than dorsal surface of terga. T1 shortest and narrowest preabdominal tergum, dorsally distinctly separate from $\mathrm{T} 2$ which is only slightly longer but wider than $\mathrm{T} 1$. T1 and T2 together distinctly longer than T3; T3-T5 subequal in length or T5 somewhat longer (longest abdominal tergum) but always narrower than T3 or T4. Preabdominal sterna very pale ochreous-yellow, relatively small and narrow, becoming wider posteriorly (S5 widest); S1 short, slightly transverse and hairless, with darker stripe along posterior margin; S2 about as long as broad and slightly darkened anteriorly; S3 and S4 as long as broad or slightly longer than broad; S5 largest, somewhat wider than long and trapezoidal (posteriorly wider). S2-S5 finely setose.

Postabdomen. T6 bare, short, transverse, somewhat asymmetrical (tapered on left side), having medial quarter membranous and unpigmented (Fig. 4); its lateral parts brown and well sclerotized, with right part reaching farther ventrally (cf. Fig. 5). S6-S8 strongly asymmetrical, brown to dark brown, partly coalesced dorsally; S6 (Figs 5, 7) short and transverse, with strongly sclerotized and blackish brown anterior marginal ledge; S7 longer (Fig. 7) but also anteriorly (more narrowly) dark-margined; S6 and S7 with 2 setae each; S8 larger than S7, situated dorsally but less asymmetrical (Figs 4, 5), with sparse (7 or 8) setae, situated mainly posteriorly.

Genitalia. Epandrium (Figs 6, 8) relatively small compared to internal genitalia, relatively broad, wider than high, with sparse setae, dorsolateral seta most robust and longest; dorsal margin of epandrium very slightly convex; anal fissure (Fig. 6) not large and rather narrow, subovoid (ventrally open). Cercus (Fig. 6, ce) small, wider anteriorly (internally) than posteriorly or laterally; its posterior side shortly and finely setose. Medandrium (Figs 6, 8, ma) with deep and narrow subrectangular ventromedial incision and with dorsolateral corners slightly projecting laterally. Gonostylus (Figs 6, 8-9) relatively short and broad, with anteroventral apex bent medially and convex both anteriorly and posteriorly (Fig. 9), micropubescence covering most of outer side except for narrow anterior margin and narrowed but rounded apex; setae on inner side longer but fine and relatively sparse. Internal genitalia comparatively large. Hypandrium (Fig. 10) relatively robust, very slightly sinuate in lateral view and more robust in posterior half; internal hypandrial lobes (Fig. 10, hl) distinct but submembranous and pale-pigmented. Transandrium relatively broad but slender (Fig. 11, ta), with medial caudal process forked, micropubescent but weakly sclerotized (Fig. 11, cp); basal membrane (Fig. 11, bm) with transverse spine-like tubercles arranged in two groups on arms of caudal fork. Pregonite (Fig. 10, prg) developed as distinctly separate lobe, posteroventrally somewhat projecting and carrying 9 or 10 setae (half of them internal and shorter). Postgonite (Fig. 10, pg) relatively large and of complex construction; its darker proximal part expanded ventrally and with 4 short setae on inner side of anterior margin; its distal part paler, projecting in two lobes: longer anterior lobe with rounded apex, 1 strong anterior seta and some sensilla on outer side, and shorter, bare posterior lobe, subtriangular in profile. Aedeagal complex (Fig. 13). Phallapodeme relatively strong, with deeply forked, almost symmetrical proximal end, rather simple apex and slender fulcrum (Fig. 13, fc). Aedeagal part of folding apparatus (Fig. 13, afa) well sclerotized and dark-pigmented (particularly dorsally); its external side with dark tuberculiform excrescences (largest anterodorsally); connecting sclerite paler, long and slender, with surface plain. Phallophore short, compact, slightly projecting posteroventrally (Fig. 13, pp) and with small anterior sclerite connecting it with base of phallapodeme. Basal part of distiphallus distinctly sclerotized both dorsally (base of saccus) and ventrally (base of filum). Saccus of distiphallus relatively large (Fig. 13, s), dorsally and laterobasally more or less sclerotized; membranous part of saccus dilated distally and provided with sparse hyaline tubercles, mainly anteriorly. Filum of distiphallus (Fig. 13, f) rather compact, long and well sclerotized, beginning just below phallophore, relatively slender, bent ventrally but bifid in distal fourth or fifth, thus with shorter hooked, apically 
acutely pointed projection and longer, thicker main branch with somewhat dilated, flattened and curved but hairless apex (Fig. 12). Ejacapodeme distinct, with digitiform projection distally (Fig. 13, ea).

Female $(n=156)$

Similar to male unless mentioned otherwise.

TOTAL BODY LENGTH. $1.66-2.38 \mathrm{~mm}$.

HEAD. Antenna darker, orange-ochreous (Fig. 14), with $1^{\text {st }}$ flagellomere often narrowly brownish darkened on anterior margin (also on inner side). Also frons anteromedially often darker, orange. Peristomal setulae more numerous (up to 6) in large specimens.

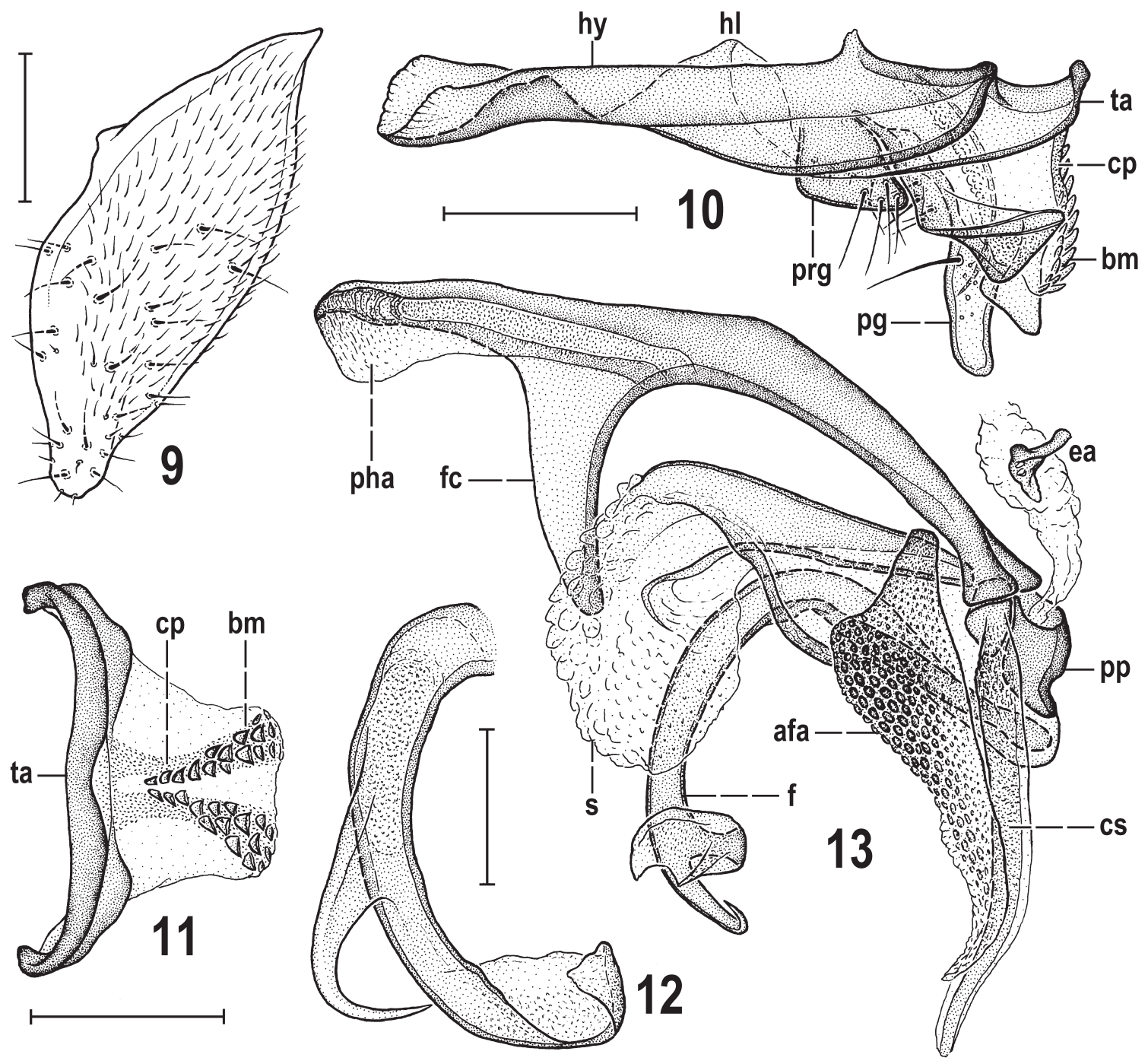

Figs 9-13. Mumetopia interfeles Roháček sp. nov., male paratypes (SMOC MIT005, MIT006). 9. Gonostylus, posterolateroventral view (widest extension view). 10. Hypandrial complex, lateral view. 11. Transandrium, caudal view. 12. Filum of distiphallus, anteroventral view. 13. Aedeagal complex, lateral view. Scale bars: 9, $12=0.05 \mathrm{~mm} ; 10-11,13=0.1 \mathrm{~mm}$. For abbreviations see Material and methods. 
Thorax. Thoracic pattern more variable: notopleural area sometimes partly or entirely yellow and dorsal brownish stripe on pleuron reduced to small spots or faded (Fig. 14), with propleuron completely yellow. Sternopleuron sometimes with more numerous microsetae.

LEGS. Ventroapical seta on $\mathrm{t}_{2}$ often somewhat longer; $\mathrm{f}_{3}$ lacking thickened shortened setae in posteroventral row, uniformly shortly setulose.

WING (Fig. 15). Larger than in male on average. Wing measurements: length 1.59-2.32 mm, width $0.55-0.81 \mathrm{~mm} ; \mathrm{Cs}_{3}: \mathrm{Cs}_{4}=1.02-1.26 ; \mathrm{r}-\mathrm{m} \backslash \mathrm{dm}-\mathrm{cu}: \mathrm{dm}-\mathrm{cu}=2.33-3.31$.

ABDOMEN. Wider (Figs 16-17) and, consequently, all preabdominal terga (T1-T5) wider and more transverse than in male. T1-T5 dorsomedially broadly pale ochreous to yellow (Fig. 16), only laterally to laterodorsally brown to dark brown, or with narrow medial brownish band in addition (see Fig. 17); T5 most variable in colouration, its mediodorsal surface ranging from largely ochreous-yellow to entirely brown (almost concolourous with sides, Fig. 14) but usually bicolourous (Fig. 16), with dark parts enlarged and broadly connected posteriorly (Fig. 17). T1 and T2 dorsally separate (Figs 16-17), only laterally coalesced. T1 smallest and shortest of preabdominal terga. T2 slightly narrower and shorter than T3; T3-T5 subequal in length or T5 somewhat longer, T3 and/or T4 widest, T5 distinctly narrower than T4 and more or less tapered posteriorly. Preabdominal sterna very pale (Fig. 14), whitish with ochreous tinge. S1 very similar to that of male. S2-S5 becoming only slightly wider posteriorly but subequal in length. S2 and S3 about as long as broad, S4 slightly wider than long, all suboblong. S5
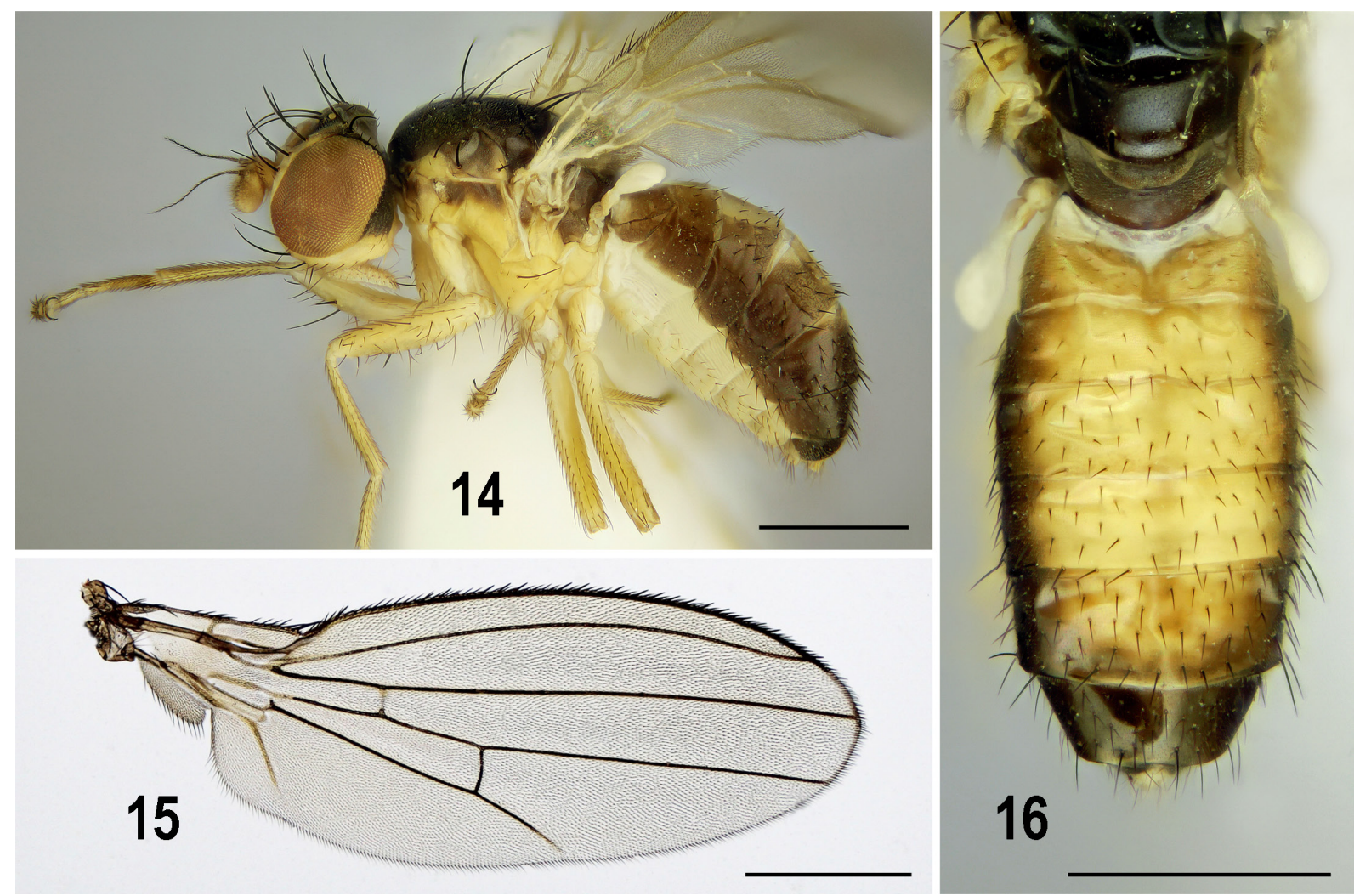

Figs 14-16. Mumetopia interfeles Roháček sp. nov., female paratypes (SMOC MIT076-MIT078). 14. Body of aberrant specimen, lateral view. 15. Right wing. 16. Posterior part of thorax and abdomen, dorsal view. Scale bars $=0.5 \mathrm{~mm}$. Photos by P. Krásenský. 


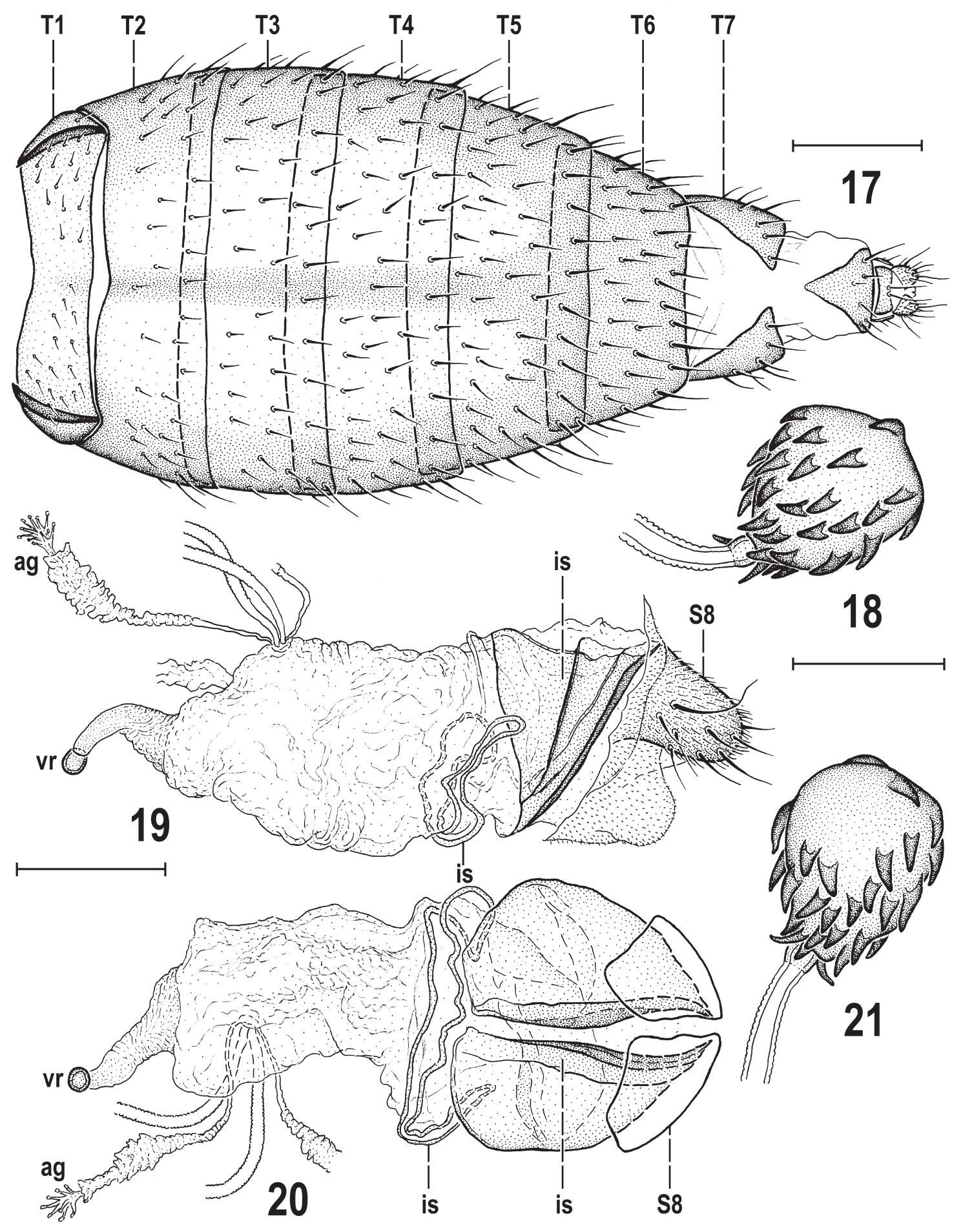

Figs 17-21. Mumetopia interfeles Roháček sp. nov., female paratypes (SMOC MIT080-MIT083). 17. Abdomen, dorsal view. 18, 21. Spermatheca. 19. Genital chamber and $S 8$, lateral view. 20. Same, ventral view (setosity of S8 omitted). Scale bars: $17=0.2 \mathrm{~mm} ; 18,21=0.05 \mathrm{~mm} ; 19-20=0.1 \mathrm{~mm}$. For abbreviations see Material and methods. 
more distinctly wider than long and with sides more rounded, thus resembling in shape and size S6. Setosity of preabdominal terga and sterna as in male.

Postabdomen (Figs 23-25). T6 uniformly dark brown (see Fig. 24), transversely trapezoidal, tapered posteriorly and shortly setose in posterior two-thirds. S6 transversely suboblong with rounded corners, pale ochreous yellow, with rather sparse and long setae. T7 and S7 separate (Figs 23, 25). T7 blackish brown, darker than T6, dorsomedially broadly divided (see Fig. 24) and its lateral part on each side reaching far ventrally, having $7^{\text {th }}$ spiracle embedded in anteroventral corner (Fig. 25) and having setae in posterior half to two-thirds. S7 relatively large and long (Fig. 25), ochreous, elongately suboblong, with posterior half somewhat narrower, with fine long setae in posterior micropubescent half. Micropubescence in membrane between ventral margins of T7 and S7 more or less enlarged. T8 dark brown, subtriangular, with anterior corner acutely pointed (Fig. 24), entirely micropubescent and with a few fine setae posterolaterally. S8 short, medially divided (Fig. 25) and posteriorly bent dorsally, finely setose and micropubescent (see also Fig. 19). Internal sclerites of genital chamber (Figs 19-20) distinct but not heavily sclerotized, only pale brown, formed by a pair of complex posterior sclerites (obviously a fusion of 2 pairs of sclerites) and by 1 anterior, very slender (poorly visible because pale pigmented), transversely compressed and dorsolaterally bent annular sclerite. Ventral receptacle (Figs 19-20, vr) small, subspherical, rather weakly sclerotized and pale brown, set on short, bent, distally tapered membranous duct. Remnant of accessory gland small (Figs 19-20, ag), formed by tuft of minute digitiform processes with globulate apices on subterminally slightly dilated duct. Spermathecae $(1+1)$ shortly pyriform (Figs 18,21), with small, short and pale duct cervix, and with dense robust dark spines on most of surface. T10 (Fig. 24) very short and transverse, relatively dark-pigmented, with 2 long, closely arising, posteromedial setae and very sparse fine micropubescence. S10 much larger than T10, roughly pentagonal but with distinctly emarginate anterior margin, rounded posteriomedial corner and micropubescent on most of its surface (Fig. 25). Cercus small, short (Figs 23-24, ce), with rich setae (apical, dorsopreapical and lateral setae rather subequal in length) and very fine micropubescence.

\section{Biology}

The new species was found to be associated with a grass growing in a courtyard (shared backyard) between houses in the Cerro O'Higgins area of the city of Valparaíso (Fig. 30) in February. Subsequently, when plant specimens with mature inflorescences from this lawn were available for study, the grass was identified by Chilean botanists V.L. Finot Saldías and P.H. Peñailillo Brito as Hordeum murinum L. (Mouse Barley, Hare Barley, Wall Barley, etc.). This wild barley is native to the W Palaearctic (probably originally Mediterranean) but also grows as a naturalized alien species in many other parts of the world, including South America. It has been known to occur in Chile since 1854 (Ugarte et al. 2011) and is now common in central Chile (Navas 1966). Hordeum murinum is a common component of ruderal flora in urban and other anthropogenic habitats in Europe as well as in central Chile (Gärtner et al. 2015) where it can also occur in wetland habitats (cf. Del Campo et al. 2005).

A total of 356 specimens of $M$. interfeles sp. nov. was swept by M. von Tschirnhaus from this grassy habitat covering an area of ca $55 \mathrm{~m}^{2}$, bordered by fencing and sidewalks (Fig. 31), and frequently visited by cats and dogs (cat and dog droppings present). This provides an estimate of density of $356 / 55=$ $6.5 \mathrm{flies} / \mathrm{m}^{2}$. However, the material he collected was obtained with only two sweep catches (each less than 5 minutes long and similarly numerous), so many more specimens (he estimated over 1000) occurred in the collecting spot (M. von Tschirnhaus, pers. com. 2018, 2020). Thus, the actual minimum density of the species was likely three times this estimate.

The total sample of insects swept by M. von Tschirnhaus from H. murinum in this locality comprised 1478 specimens (Diptera 1091, Hemiptera 288, Hymenoptera 66, Collembola 16, Coleoptera 9, Thysanopera 8). Diptera were dominated by Chloropidae (419), Anthomyzidae (356, M. interfeles sp. nov. only) 


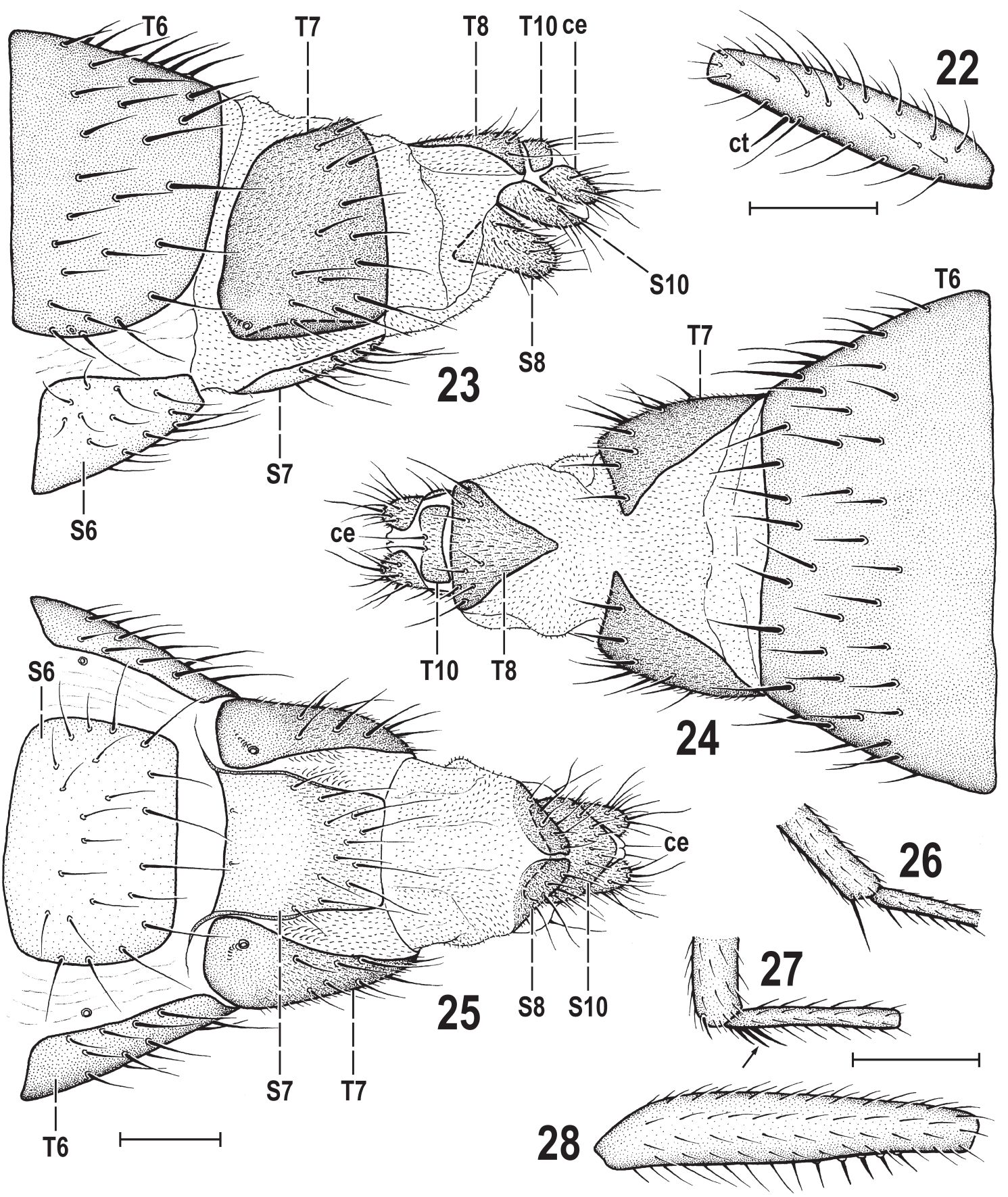

Figs 22-28. Mumetopia interfeles Roháček sp. nov., paratypes (SMOC MIT002-MIT006, MIT081MIT083). 22. 0 , $\mathrm{f}_{1}$, posterior view. 23. Female postabdomen, lateral view. 24. Same, dorsal view. 25. Same, ventral view. 26. Apex of male $t_{2}$ and base of mid basitarsus, anterior view. 27. Apex of male $\mathrm{t}_{3}$ and hind basitarsus with 3 thickened ventrobasal setulae (black arrow), anterior view. 28. Male $\mathrm{f}_{3}$, anterior view. Scale bars: $22,26-28=0.2 \mathrm{~mm} ; 23-25=0.1 \mathrm{~mm}$. For abbreviations see Material and methods. 


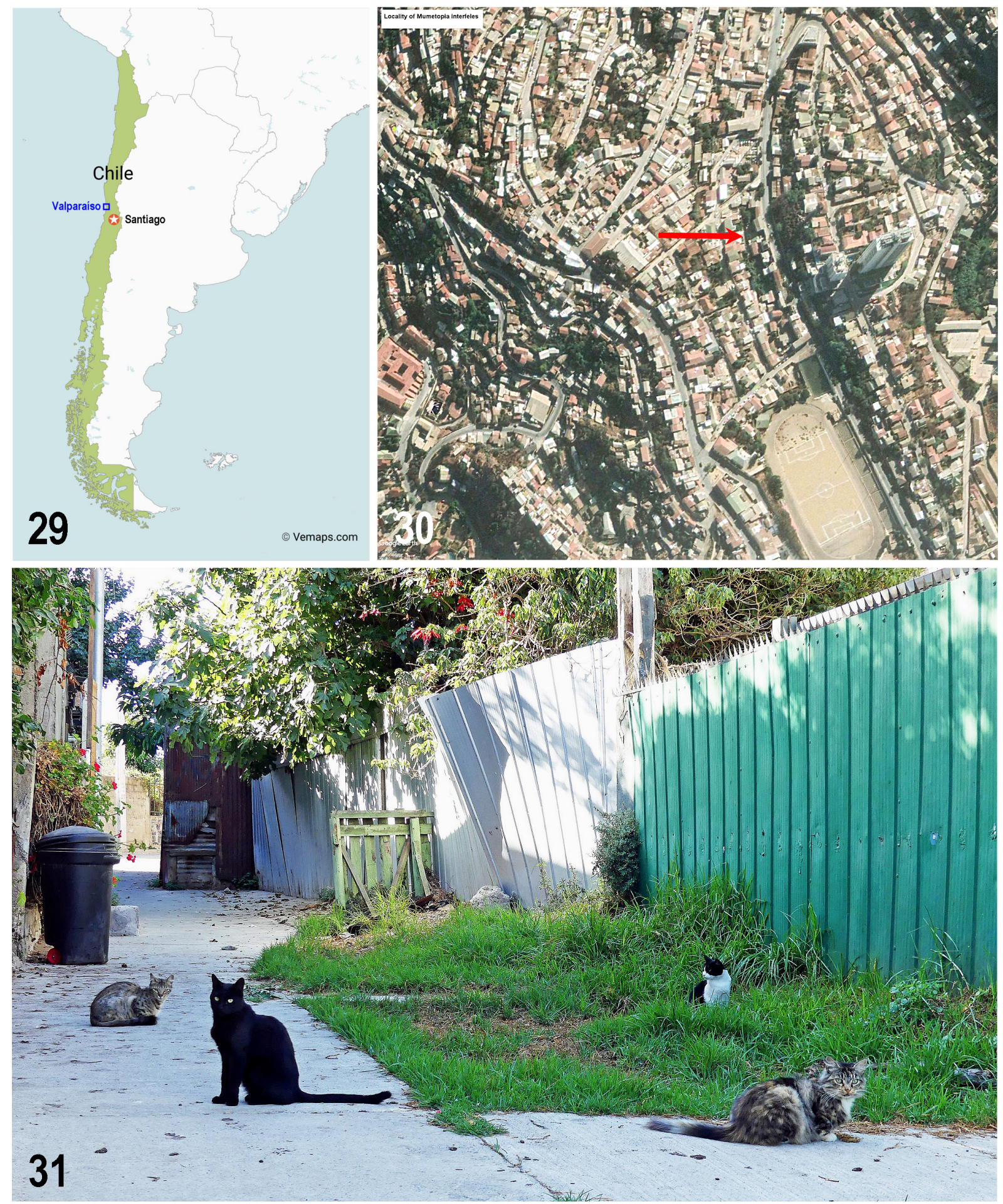

Figs 29-31. Maps and habitat. 29. Map of Chile with position of type locality of Mumetopia interfeles Roháček sp. nov. (blue open square). 30. Satellite view of part of Valparaíso city, with collecting site indicated by red arrow. 31. Habitat of $M$. interfeles sp. nov., northern end of grassy area between houses visited by cats. Photo by J. von Tschirnhaus (31), other sources: Vemaps.com (29), Google Earth Pro (30). 
and Drosophilidae (217, species of Scaptomyza only) while other families were represented by only a few specimens each (Sphaeroceridae 34, Lonchopteridae 13, Phoridae 11, Cecidomyiidae 10, Trixoscelididae 9, Chironomidae 7, Culicidae 4, Mycetophilidae 3, Scatopsidae 2, Lauxaniidae 2, Ephydridae 2, Ceratopogonidae 1, Tephritidae 1). Apart from M. interfeles sp. nov., only one other species occurred en masse in this growth of H. murinum, viz., the neotropical chloropid Ceratobarys

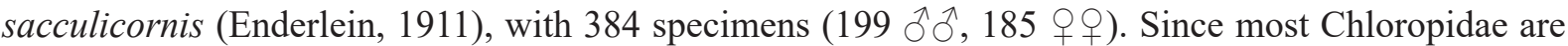
phytophages as larvae, $C$. sacculicornis most likely develops on this grass. This would also position the Chloropidae as the most important component of the fly community associated with H. murinum here. Besides the above species, specimens of three more chloropid species were found, viz., Opetiophora

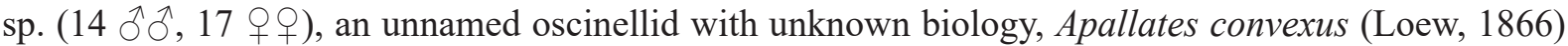
(3 $\hat{\partial} \widehat{\delta})$ and Diplotoxa sp. $(1 \hat{\jmath})$. Interestingly, the genus Opetiophora has not been previously reported from South America (M. von Tschirnhaus, pers. com. 2020).

\section{Distribution}

Central Chile, commune of Valparaíso (Fig. 29, blue open square).

\section{Discussion}

\section{Phylogeny and classification}

The relationships of the new species have been tested by means of molecular data analyses (BI and RAxML). The addition of two species, Stiphrosoma stylatum and M. interfeles sp. nov., to the analysis has had no extraneous effect on the general topology of the tree published by Barber \& Roháček (2020). Stiphrosoma stylatum is clearly recognised as a sister species to $S$. cingulatum (Haliday, 1855) in both hypotheses (Figs 32-33). Similarly, M. interfeles sp. nov. is resolved as a sister species of M. occipitalis in the Mumetopia - Stiphrosoma clade. This clade is represented (in these hypotheses) by terminal taxa of the genera Mumetopia, Stiphrosoma and the Mumetopia nigrimana group, all belonging to the Chamaebosca group of genera, while a representative of the genus Chamaebosca is hitherto absent from the dataset analysed. The Chamaebosca group of genera has recently been confirmed as a sister group of the genus Carexomyza Roháček, 2009 (see Barber \& Roháček 2020). Despite M. interfeles sp. nov. and $M$. occipitalis being of similar external appearance, they are not very closely related, as indicated by their relatively long terminal branches (see Figs 32-33).

Detailed examination of morphological structures of the male and female terminalia (see above) revealed some distinct differences from those in M. occipitalis and both its brachypterous high-montane Andean relatives, viz., M. messor and M. taeniata (cf. Roháček \& Barber 2009). The construction of the filum (bare, with short curved projection), the male cercus (almost normally positioned) and the internal sclerotization of the female genital chamber (posterior pair of sclerites relatively short) indicate that $M$. interfeles sp. nov. belongs to the "genus $M$ " of Roháček \& Barber (2009) and Barber \& Roháček (2010). However, the above characters shared by $M$. interfeles sp. nov. and the "genus $M$ " and delimiting the latter group are all plesiomorphic in the morphological hypothesis of Roháček \& Barber (2009). The absence of distinct synapomophies for the "genus $M$ " prevents delimitation of this group as a monophyletic taxon. Moreover, the general construction of male and female terminalia do not differ significantly in species of the genus Mumetopia (s. str.), "genus $B$ " and "genus $M$ " (of Roháček \& Barber 2009) which together form a clade well supported by several synapomorphies in the male genitalia (viz., postgonite complex, with different proximal and distal parts; postgonite with several setae; medandrium with dorsolateral corners projecting; aedeagal part of folding apparatus dorsally sclerotized; filum with slender projection in distal third), cf. Fig. 34. For both above reasons, it is suggested to expand the taxonomic limits of the genus Mumetopia (without the M. nigrimana group, of course) to include all three above lineages, thus also the "genus $M$ " and the "genus $B$ ", in spite of the fact that the latter group is formed by species externally strikingly dissimilar (large, pale, very strongly setose species, 


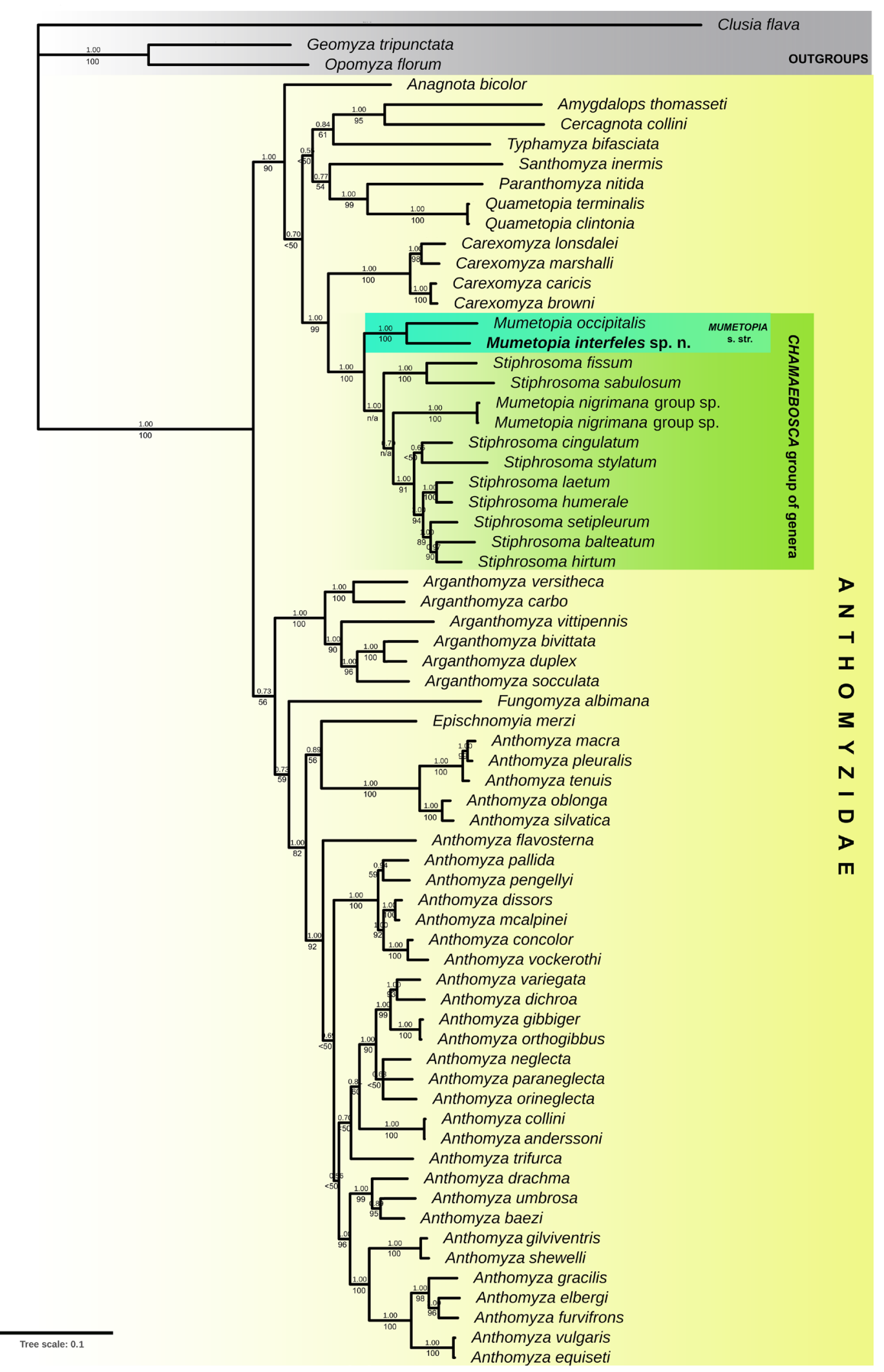

Fig. 32. Bayesian hypothesis for relationships of 64 species of Anthomyzidae based on DNA sequence data $(12 \mathrm{~S}, 16 \mathrm{~S}, 28 \mathrm{~S}$, COI, COII, CytB, ITS2) representing 4583 characters. Numbers above nodes $=$ posterior probability values if $>0.5$, and below nodes $=$ bootstrap support values for RAxML. 
with prs and costal spines enlarged) to those belonging to the two other branches. However, these two unnamed species ("genus $B$ ", endemic to Juan Fernández Islands, Chile; see Roháček \& Barber 2009; Barber \& Roháček 2010) could be considered only aberrant descendants of Mumetopia which have been (externally) markedly modified in the course of extended insular isolation. The construction of male and female terminalia (including a number of apomorphic structures), so closely similar in $M$. occipitalis (and its closest relatives) and both species of the "genus B", seems to demonstrate this. A broader concept of Mumetopia (s. str.) was already suggested by Roháček \& Barber (2009: 214) as one alternative way to classify this group based on the analysis of 27 morphological characters (see Fig. 34). It can be expected that future molecular studies of more (than one) species of all these lineages and also of the M. nigrimana group (which remains unsettled with respect to species of Stiphrosoma, cf. Figs 32-34) will better clarify their mutual relationships. However, to achieve this goal, fresh specimens of these Neotropical species must be obtained to expand the current molecular dataset of Anthomyzidae.

\section{Mass occurrence of adult anthomyzid flies}

As mentioned above in the Introduction, adults of Anthomyzidae are rarely encountered and collected in large numbers. Published records of more than 300 specimens of a species in a single limited area are very unusual while those with fewer to ca 200 specimens are more frequent (see Introduction). However, the definition of 'mass occurrence' is yet more problematic when evaluated with respect to

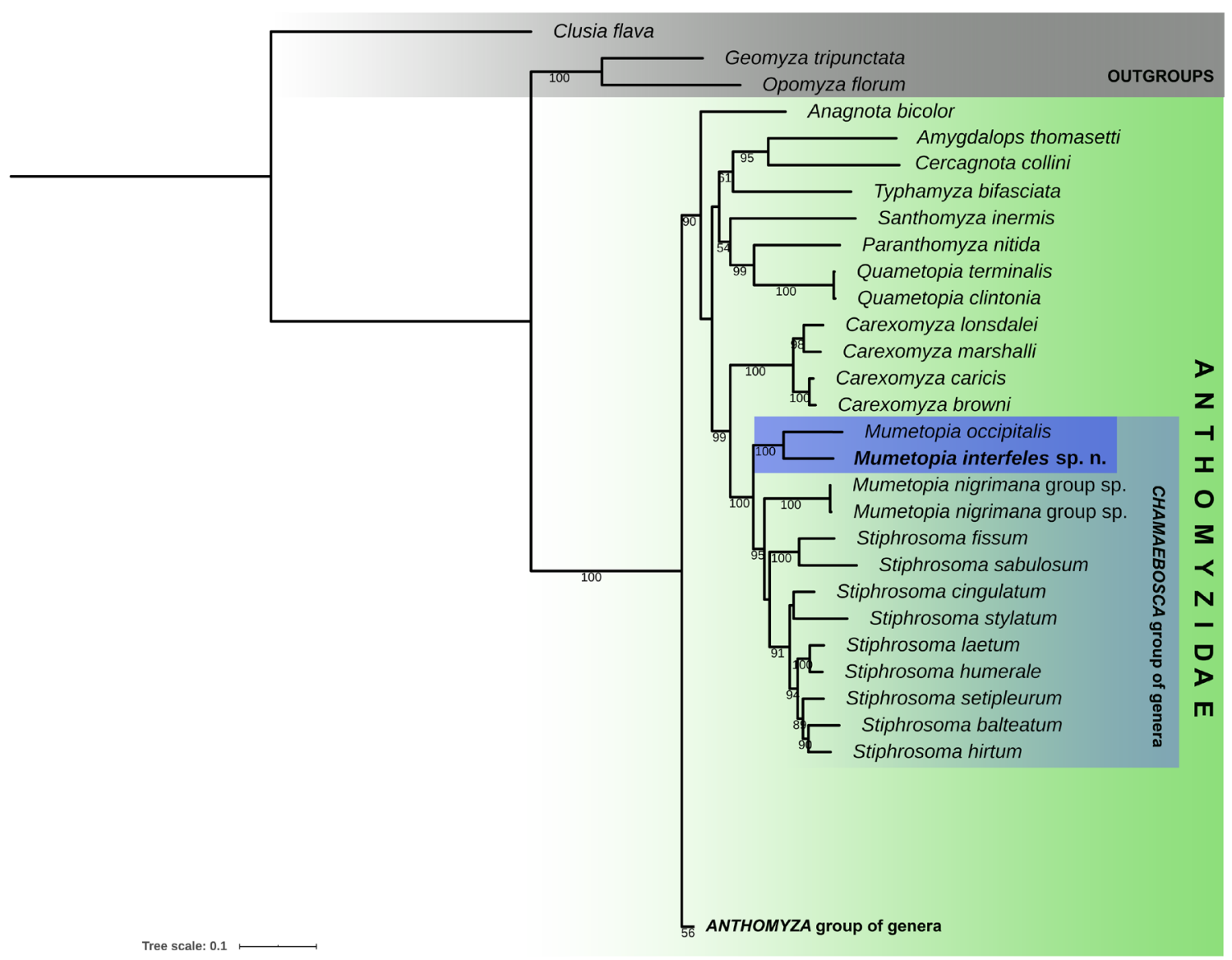

Fig. 33. RAxML hypothesis for relationships of Anthomyzidae based on DNA sequence data (12S, 16S, 28S, COI, COII, CytB, ITS2) representing 4583 characters, without the Anthomyza group of genera clade displayed. Numbers below nodes $=$ bootstrap support values. 
the density of specimens (per $\mathrm{m}^{2}$ ) and duration of collecting. For example, the terricolous species of Stiphrosoma, being closely associated with the basal parts of tufts of graminoids, can often occur in high density because a small sample of grass can be inhabited by a few tens of specimens (known in $S$. sabulosum (Haliday, 1837), S. laetum, S. cingulatum; Roháček 2009 and unpublished data), and hence their densities can be over 100 specimens $/ \mathrm{m}^{2}$ although the collection of more than 200 specimens could be difficult and time-consuming in the site. The same applies to time and effort of sampling with extended time and effort it would surely be possible to capture hundreds of specimens of various common but also rare (localized) species in a suitable seasonal period, site and habitat. Some records of large samples listed in the Introduction could be the result of such specially aimed and timed collections.

Considering all these circumstances, the clearest examples of mass occurrence can obviously be ascribed to only two or three cases:

(1) the record of an unusually large sample of Amygdalops cuspidatus (546 specimens) plus 187 specimens of other species of Amygdalops Lamb, 1914, viz., A. nigrinotum Sueyoshi \& Roháček, 2003 (155), A. lineola de Meijere, 1916 (4), A. sevciki Roháček, 2018 (erroneously reported as A. bisinus by Roháček 2008) (2) and Amygdalops sp. indet. (damaged) (26), for a total of 733 specimens of Anthomyzidae in Flores Island, Indonesia, collected by M. von Tschirnhaus (see Roháček 2008, 2018). The sample was obtained by sweeping vegetation (weeds and elephant grass) along a small dry stream covering an area about $4 \times 40 \mathrm{~m}\left(160 \mathrm{~m}^{2}\right)$ and lasting about 10 minutes but by far not all Anthomyzidae were aspirated from the eclector and preserved; there may have been thousands more even in the section already sampled along this stream. Despite this qualification, this family was the most abundant, forming $39.6 \%$ (A. cuspidatus 29.5\%) of all flies collected (M. von Tschirnhaus, pers. com. 2020).

(2) the sample of $M$. interfeles sp. nov. from Valparaíso, Chile, also collected by M. von Tschirnhaus, where this species formed $32.6 \%$ of the fly material collected. This case is similar to the previous one because both were made by a non-specialist in Anthomyzidae (aiming to collect all Diptera, not

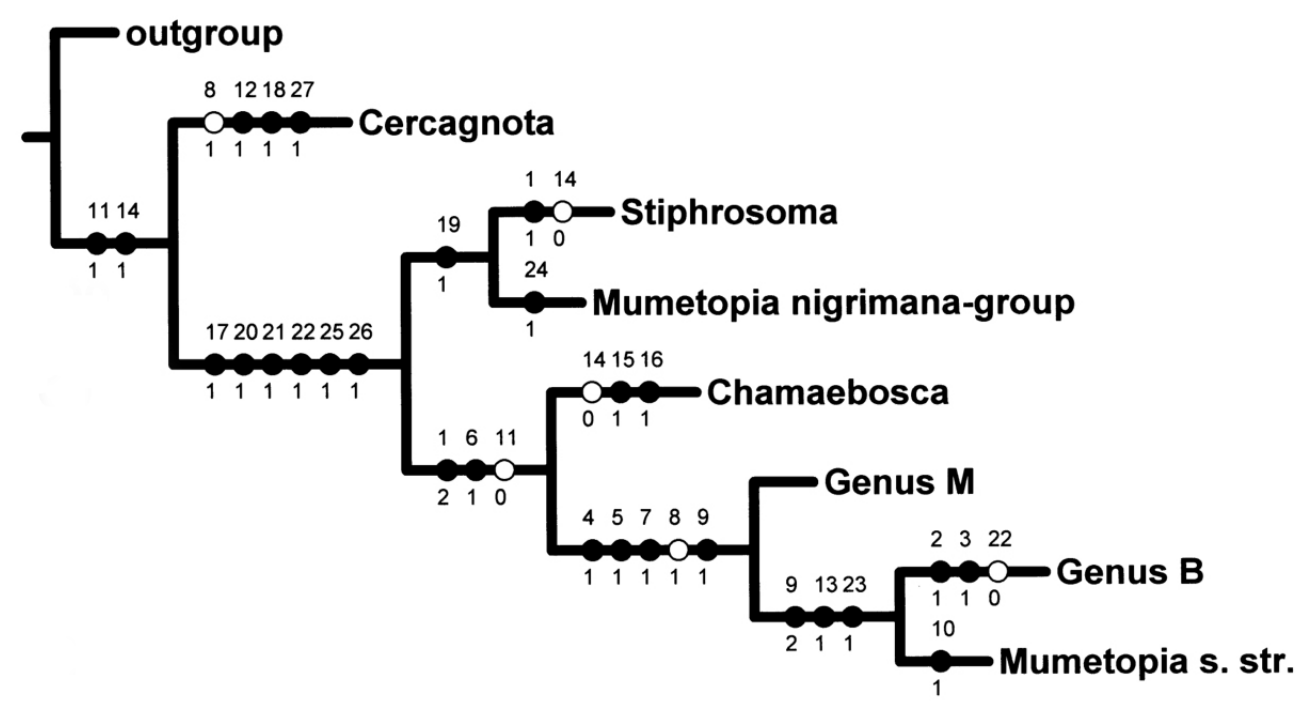

Fig. 34. Most parsimonious tree $(\mathrm{L}=34$ steps, $\mathrm{CI}=0.85, \mathrm{RI}=0.82)$ resulting from cladistic morphological analysis of the Chamaebosca clade, ACCTRAN optimization. Full circles = non-homoplasious character transformations; empty circles = homoplasious character transformations. Numbers below branches indicate change to apomorphic $(1,2)$ or plesiomorphic $(0)$ states of characters (reversals in case of $(0)$ ). Adapted from Roháček \& Barber (2009: fig. 38). 
specifically Anthomyzidae) and achieved by sweeping for a very short time period. Both cases are also similar in that the irruption of a local population of an anthomyzid species occurred in an anthropogenic environment but differ in that one is from an agricultural setting while the other is from an urban setting.

(3) the third possible case of mass occurrence can be the record of large numbers of specimens of Stiphrosoma laetum reared by H. Meyer from tufts of grasses in Germany (see example of his results in Introduction) where all insects emerging from samples of plants were collected. In this case, however, the method and habitat (a natural rivershore marsh) were different, and therefore, it is not wholly comparable with the two previous cases.

The occurrence of Anthomyzidae within urban habitats, particularly those degraded in residential areas (thus excluding the occurrences in parks or marginal semi-urban areas of towns), also seems to be somewhat unusual. It was previously known only for Stiphrosoma sabulosum in Canada and the United States of America, where this species was found several times in disturbed urban habitats (Roháček \& Barber 2005). However, Barber \& Roháček (2010: 1079) reported that also some species of the M. nigrimana group (also belonging to the Chamaebosca group of genera) can sometimes be encountered in urban habitats where they can occur in long grasses in disturbed sites very similar to that described above for $M$. interfeles sp. nov. Thus, most anthomyzid flies with adults occurring in disturbed residential habitats belong to the Chamaebosca group of genera (species of Stiphrosoma and Mumetopia). I agree with K.N. Barber (pers. com. 2020) that the occurrence and persistence of these species in residential areas can be a consequence of the conservation of the lower portions of the host grasses (or other graminoids) even after successive mowings, and localized concentrations might be the result of a flushing/concentrating effect of mowing. So long as the roots and duff layer are not significantly disturbed, the flies can persist close to the ground in contrast to other Anthomyzidae which might not survive lawn mowing or might vacate as adults.

The mass occurrence of $M$. interfeles sp. nov. in a residential area of Valparaíso is significant on its own merit for the large numbers of specimens so readily collected from a small area. However, this surely native Chilean species is also notable for having developed here on an alien invasive (although naturalized) grass species, Hordeum murinum.

\section{Acknowledgements}

We are most grateful to Michael von Tschirnhaus (Bielefeld, Germany), the collector of the new species, and his son, Jakob von Tschirnhaus (Valparaíso, Chile), for enabling study of this interesting material of Anthomyzidae, provision of biological data about its occurrence, for mediating the identification of the host plant, permission to use their photos and critical reading of an early draft of the manuscript. Pavel Krásenský (Chomutov, Czech Republic) is cordially thanked for high-quality photographs of adults of the new species, Victor Lionel Finot Saldías (Concepción, Chile) and Patricio Humberto Peñailillo Brito (Talca, Chile) for the identification of the host grass of the new species, and Kevin N. Barber (Sault Ste. Marie, Canada) for provision of unpublished data about large occurrences of Anthomyzidae. Acknowledgements are further extended to Peter J. Chandler (Melksham, England, UK) and to both reviewers who kindly provided corrections, useful comments and suggestions to the text of the manuscript. J. Roháček's research on Anthomyzidae was financially supported by the Ministry of Culture of the Czech Republic through the institutional financing of long-term conceptual development of a research institution (the Silesian Museum, MK000100595). 


\section{References}

Barber K.N. \& Roháček J. 2010. 81: Anthomyzidae (anthomyzid flies). In: Brown B.V., Borkent A., Cumming J.M., Wood D.M., Woodley N.E. \& Zumbado M.A. (eds) Manual of Central American Diptera. Vol. 2: 1073-1081. NRC Research Press, Ottawa.

Barber K.N. \& Roháček J. 2020. Revision of Carexomyza Roháček with descriptions of three new Nearctic species (Diptera: Anthomyzidae). Arthropod Systematics \& Phylogeny 78 (1): 69-109. https://doi.org/10.26049/ASP78-1-2020-04

Cumming J.M. \& Wood D.M. 2009. 2. Adult morphology and terminology. In: Brown B.V., Borkent A., Cumming J.M., Wood D.M., Woodley N.E. \& Zumbado M.A. (eds) Manual of Central American Diptera. Vol. 1: 9-50. NRC Research Press, Ottawa.

Cumming J.M. \& Wood D.M. 2017. 2. Adult morphology and terminology. In: Kirk-Spriggs A.H. \& Sinclair B.J. (eds) Manual of Afrotropical Diptera. Vol. 1: Introductory Chapters and Keys to Diptera Families. Suricata 4: 89-133. SANBI Publishing, Pretoria.

Del Campo P., Luebert F. \& Teillier S. 2005. Asociaciones vegetales de la Laguna de Batuco, Región Metropolitana, Chile. Chloris Chilensis 8 (1) unpaginated.

Available from http://www.chlorischile.cl/batucopaula/batucoweb.htm [accessed 7 Jan. 2021].

Gärtner E., Rojas G. \& Castro S.A. 2015. Compositional patterns of ruderal herbs in Santiago, Chile. Gayana Botánica 72 (2): 192-202. https://doi.org/10.4067/S0717-66432015000200003

Griffiths G.C.D. 1972. The Phylogenetic Classification of Diptera Cyclorrhapha with Special Reference to the Structure of the Male Postabdomen. Dr. W. Junk N.V., The Hague.

Letunic I. \& Bork P. 2016. Interactive tree of life (iTOL) v3: An online tool for the display and annotation of phylogenetic and other trees. Nucleic Acids Research 44: 242-245. https://doi.org/10.1093/nar/gkw290

McAlpine J.F. 1989. 116. Phylogeny and classification of the Muscomorpha. In: McAlpine J.F. \& Wood D.M. (eds) Manual of Nearctic Diptera. Vol. 3: 1397-1518. Agriculture Canada Monograph No. 32, Minister of Supply and Services Canada, Ottawa.

Melander A.L. 1913. A synopsis of the dipterous groups Agromyzinae, Milichiinae, Ochthiphilinae and Geomyzinae. Journal of the New York Entomological Society 21: 283-300.

Navas E. 1966. Gramíneas de los alrededores de Santiago. Moliniana 3: 15-26.

Roháček J. 1998. Taxonomic limits, phylogeny and higher classification of Anthomyzidae (Diptera), with special regard to fossil record. European Journal of Entomology 95: 141-177.

Roháček J. 2006. A monograph of Palaearctic Anthomyzidae (Diptera) Part 1. Časopis Slezského zemského muzea, Opava (A) 55 (supplement 1): 1-328.

Roháček J. 2008. Revision of the genus Amygdalops Lamb, 1914 (Diptera, Anthomyzidae) of the Oriental, Australasian and Oceanian Regions. Acta Zoologica Academiae Scientiarum Hungaricae 54: 325-400.

Roháček J. 2009. A monograph of Palaearctic Anthomyzidae (Diptera) Part 2. Časopis Slezského zemského muzea, Opava (A) 58 (supplement 1): 1-180.

Roháček J. 2018. First Anthomyzidae (Diptera) from China: a new genus, six new species and new records. Acta Entomologica Musei Nationalis Pragae 58: 35-76.

https://doi.org/10.2478/aemnp-2018-0007

Roháček J. \& Barber K.N. 2005. Revision of the New World species of Stiphrosoma Czerny (Diptera: Anthomyzidae). Beiträge zur Entomologie 55 (1): 1-107.

https://doi.org/10.21248/contrib.entomol.55.1.1-107 
Roháček J. \& Barber K.N. 2009. New reduced-winged species of Mumetopia Melander, with analysis of the relationships of this genus, Chamaebosca Speiser and allied genera (Diptera: Anthomyzidae). Acta Societatis Zoologicae Bohemicae 72 (3-4) [2008]: 191-215.

Roháček J. \& Barber K.N. 2011. Quametopia, a new genus of Nearctic Anthomyzidae (Diptera), with description of two new species, immature stages and life history. European Journal of Entomology 108: 287-326. https://doi.org/10.14411/eje.2011.038

Roháček J. \& Barber K.N. 2016. Nearctic Anthomyzidae: a monograph of Anthomyza and allied genera (Diptera). Acta Entomologica Musei Nationalis Pragae 56 (supplementum): 1-412.

Roháček J. \& Tóthová A. 2014. Morphology versus DNA - what will bring clarity to the relationships of phylogenetically unclear genera of Anthomyzidae (Diptera)? Arthropod Systematics \& Phylogeny 72: $165-176$.

Roháček J., Petráková L. \& Tóthová A. 2019. Molecular phylogeny and timing of evolution of Anthomyza and related genera (Diptera: Anthomyzidae). Zoologica Scripta 48 (6): 745-760.

https://doi.org/10.1111/zsc.12373

Ugarte E., Lira F., Fuentes N. \& Klotz S. 2011. Vascular alien flora, Chile. Check List 7 (3): 365-382. https://doi.org/10.15560/7.3.365

Zatwarnicki T. 1996. A new reconstruction of the origin of eremoneuran hypopygium and its implications for classification (Insecta: Diptera). Genus 7 (1): 103-175.

Manuscript received: 17 August 2020

Manuscript accepted: 10 November 2020

Published on: 21 January 2021

Topic editor: Nesrine Akkari

Section editor: Torbjørn Ekrem

Desk editor: Radka Rosenbaumová

Printed versions of all papers are also deposited in the libraries of the institutes that are members of the EJT consortium: Muséum national d'histoire naturelle, Paris, France; Meise Botanic Garden, Belgium; Royal Museum for Central Africa, Tervuren, Belgium; Royal Belgian Institute of Natural Sciences, Brussels, Belgium; Natural History Museum of Denmark, Copenhagen, Denmark; Naturalis Biodiversity Center, Leiden, the Netherlands; Museo Nacional de Ciencias Naturales-CSIC, Madrid, Spain; Real Jardín Botánico de Madrid CSIC, Spain; Zoological Research Museum Alexander Koenig, Bonn, Germany; National Museum, Prague, Czech Republic. 